\title{
Research on the Innovation Ability of Postgraduates in Local Universities
}

\author{
Liping Lin \\ School of Economics and Management, \\ Guangxi University of Science and Technology \\ Liuzhou, China \\ 364159551@qq.com
}

\author{
Yang Wang* \\ School of Economics and Management, \\ Guangxi University of Science and Technology \\ Liuzhou, China \\ 451007352@qq.com
}

\begin{abstract}
This paper probes into the problem of graduate students' innovation ability in local universities from three aspects: first, it analyzes the concept of innovation and innovation ability; second, it sorts out the related research on the cultivation of graduate students' innovation ability in domestic universities; third, it evaluates the research on graduate students' innovation ability in domestic universities. Finally, this paper summarizes the innovation ability of postgraduates in local universities, and concludes that most of the researches in this field in recent years are qualitative and few are localized.
\end{abstract}

Keywords_Innovation; Innovation Ability; Master

\section{INNOVATION AND INNOVATION ABILITY}

\section{A. Innovation}

The term "innovation", which is often quoted in the international community, comes from the concept of innovation put forward by the Austrian-American economist (J. A. Schumpeter) Joseph Ross Schumpeter in his theory of economic development in 1912. Schumpeter believed that innovation is the production function of a new combination of production factors, and the new combination guided the use of new products, the adoption of new production methods, the opening of new markets, the acquisition of new sources of supply, and the establishment of new forms of enterprise organization [1]. He called the process of "new or recombined or rediscovered" knowledge into economic system innovation. Schumpeter's understanding of the meaning of innovation is mainly from the perspective of economics. Since Schumpeter put forward the concept of innovation, with the deepening of people's research on innovation, the connotation of innovation also has a new development. Innovation is no longer limited to the field of economics. Innovation includes a series of activities in science, technology, organization, finance and business[2]. In the modern sense, innovation means pioneering, criticizing and bringing forth the new through the old. It means the transcendence of the thoughts of predecessors, the negation and breakthrough of the existing old things, and the comprehensive embodiment of human innovation ability.

To sum up, the connotation of innovation is that in order to achieve a certain purpose, the innovation subject creates some original or innovative product that conforms to the social significance or individual value. Innovation is the whole process of knowledge innovation, achievement transformation

Innovation Project of GuangXi Graduate Education (No. JGY2018108). innovation, application of innovation and promotion of innovation. Innovation covers all fields, including scientific and technological innovation, institutional and institutional innovation, business management and cultural innovation, including humanistic knowledge and natural science knowledge innovation.

\section{B. Innovation Ability}

Innovation, also known as creation. From the Latin word creare, which means to create, produce and innovation. The modern Chinese dictionary defines it as the thought and expression of striving for innovation. According to merriamwebster, the ability to innovate is "the ability to create, to develop artistically or intellectually." So far, there is no uniform and accurate definition, and different psychologists have a great understanding and use of the term "innovation ability”.

Modern western psychologists define the ability of innovation mainly from the perspective of the product of creativity. Gruber and Wallance (1993) [3] believed that "the ability to innovate is a unity of novelty and value. Creative products should be both novel and valuable by some external standards. Feist (1993) [4] pointed out that the concept of innovation ability is "novel and suitable as a solution to problems". Martindale (1999) [5] believed that "the concept of innovation ability is specific to a specific situation, which is both novel and appropriate”. Boden (1999) [6] also elaborated that "innovation is the generation of novel and valuable ideas". Lubart (1999) [7] pointed out "from the perspective of western psychological research, the ability to innovate can be defined as the ability to produce novel and applicable work products". In particular, Nickerson (1999) pointed out "although not everyone thinks it is possible to explicitly state the objective criteria for identifying creative products, novelty is invoked as a salient feature, and the other is utility, applicability or social value".

Of course, some psychologists combined the creative process with the product to define the innovation ability. For example, Malhara (1985) pointed out that the innovation ability includes two parts: one is the process of creation, which is internal and implicit, and the second is the product of creation, which is explicit and definable.

Domestic psychologists also have a variety of different definitions of innovation ability. Cao Richang (1985) [8] 
believed that creation or creative activity is an activity that provides new, pioneering, innovative and socially meaningful products. For example, the invention of new machines, the new development of science, and the creation of literary and artistic works are creative activities in different fields of practice. Jing Qicheng (1990) [9] defined the core of innovation ability -- creative thinking, and held that creative thinking is a thinking activity that "applies unique and novel ways to solve problems". It is opposite to reconstructive thinking, which is based on abundant knowledge. It often occurs with sudden Epiphany when conventional methods fail to solve the problem. Creative thinking is necessary for all creative activities. Huang Xiting (1991) [10] believed that "creative activity is an activity that provides unique products of social value. He also pointed out" whether a product is created or not, it must not only have uniqueness, but also conform to objective laws and social value. Lin Chongde (1986) [11] defined innovation ability as "the intellectual quality of a product that is novel, unique, socially or personally valuable, using all known information for a certain purpose.” Peng Danling (1988) [12] believed that "creation or creative activity is an activity that provides novel, original and socially significant products." Taiwan psychologist Zhang Chunxing (1994) [13] believed that innovation ability can be understood in two ways. The other is the ability to use the experience to solve problems without being restricted by rules. Zhang Qinglin et al. (2002) [14] believed that the innovation ability is unique to human beings, and the psychological quality to produce novel, unique, feasible and applicable products under certain conditions. Most psychologists now agree that "the ability to innovate is the ability to create a product that is both new (original, unexpected) and appropriate (within the constraints of existing conditions, and useful)." Zhao Guirong (2002) [15] pointed out that innovation ability refers to the ability to produce new knowledge, new ideas, new methods and new achievements by using accumulated knowledge and experience to process and recreate scientifically. Li Fei (2002) [16] believed that innovation ability refers to the ability of people to solve problems creatively and uniquely and generate valuable new ideas, methods and achievements in various types of creative activities with the support of personality quality and the use of existing knowledge and experience.

\section{DOMESTIC RESEARCH ON THE CULTIVATION OF INNOVATIVE ABILITY OF POSTGRADUATES}

At present, there are many types of research on the innovation ability of postgraduates in China. Through CNKI, from 1980 to 2007, 150 articles with the title of "postgraduate innovation ability" were published in journals, master and doctoral papers, conference papers and newspapers. Among them, there are few kinds of literature about quantitative research on the characteristics of the innovation ability of postgraduates, and few literatures about systematic research on the factors influencing the cultivation of postgraduates' innovation ability and the ways and methods of cultivation.

He Dezhong and Fang Zhenyun (2004) [17] proposed that how to ensure the quality of graduate education has attracted the attention of the whole society when the scale of graduate education is developing excessively. At present, one of the main problems of the quality of postgraduate education is that the innovation ability of postgraduates is not strong. Graduate students are accustomed to receiving, understanding and mastering ready-made knowledge, lack of critical spirit and conformism, lack of original insights and original research on paper topics, and in recent years, there have been problems of academic ethics for graduate students. The phenomenon of the weak innovation ability of postgraduates must be attached great importance to all circles of graduate education.

Huang Xinming and Wang Ping (1999) [18] proposed that the main factors affecting the cultivation of graduate students' innovative ability include: the cultivation of innovative ability is not carried out throughout the graduate education; they are ignorant of the state of the scientific frontier; lack of strong academic communication atmosphere; the tutor did not deal with the relationship between his "guidance" and students' "learning" and lacked the supervision mechanism of academic papers. Zhang Yingchun and Ding Yiqiang (2000) [19] found that the negative effects of conservatism, modesty and courtesy in traditional culture. The binding effect of highly centralized and rigid education and personnel system; restrictions on the collection of books, instruments and equipment in colleges and universities; the degree of the tutor is low and the academic level is not high; the low quality of graduate students is the main reason that restricts the cultivation of graduate students' innovation ability. Qian Cunyang (2004) [20] also pointed out that the obstacles to the cultivation of graduate students' innovation ability were the uneven quality of the tutor team, the decline of the quality of students, the serious phenomenon of inbreeding, the low academic ethics of graduate students and the unreasonable training process. Ayoyo intellectual, Li Zhi (2004) [21] the study found that the bondage of traditional concept of graduate student education, graduate teaching system of the lag (such as the flaws of the personnel training mode, credits and some unreasonable curriculum, teaching methods and means lag behind), the teachers troop construction, the problems and talent management model of rigid and graduate benefits on the low side factors such as the main factor is the graduate student innovation ability training.

Based on the collected literature on the cultivation of innovative ability of postgraduates, the quality education of postgraduates is mainly implemented from one or several perspectives to ensure the cultivation of innovative ability and improve the innovative ability of postgraduates.

From the perspective of discipline construction, emphasis should be laid on the cultivation of innovative ability through discipline planning and adjustment, so as to give full play to the role of discipline groups, advocate the knowledge structure and ability structure of postgraduates, and promote the cultivation of innovative ability of postgraduates (Zhang Weigang et al. , 1999) [22]. Cultivate the creative ability of graduate students through interdisciplinary practice (Hu Zhide, 2001) [23].

From the perspective of training program and curriculum system design, by revising the training program, optimizing the structure of graduate courses, emphasizing the cultivation of 
methods and abilities, ensuring the quality of graduate education, and pushing forward the reform of graduate teaching (Ren Bing, 1999) [24].

From the perspective of academic environment and scientific research atmosphere creation, a good discipline ecological environment can be built by innovating a free and open academic environment, tracking the academic frontier, and exploring a competitive environment (Zhang Wenxiu et al., 1999) [25]. The daily education of postgraduates is carried out through the teaching and research group, which are the main collectives of study, scientific research and life. Create a good research atmosphere through the collective construction of graduate research (MaYongbin et al., 2000) [26].

From the perspective of thesis innovation and the role of tutors, the requirements for innovation and the research ability can be ensured, innovation ability and innovation spirit of postgraduates can be effectively improved by standardizing the links such as topic selection, topic proposal, research, tutor guidance and defense. (Geng Jun et al., 1999)[27]. In terms of topic selection, the tutor should guide students to the forefront of the discipline according to the characteristics of postgraduates, and encourage students to undertake risky subjects. In the paper writing stage, the graduate students have frequent contact with their tutors, often discuss problems on an equal footing, exchange opinions and participate in academic seminars (Qu Haidong et al. , 2002)[28].

From the perspective of specific teaching methods, through the reform and innovation of teaching methods, postgraduate research innovation ability can be cultivated (Yang zhenhong, 1999)[29]. There are science method courses; participatory teaching method; take the question as the guidance, take the scientific research topic as the organization form; thematic research and case study method.

From the perspective of extracurricular social practice, it expands the social vision of postgraduates and cultivates their practical ability and innovation ability by means of temporary post-training, summer social practice and social research (Yang liangqi, 1999) [30].

From the perspective of community culture, through the enrichment and standardization of community culture, emphasis should be placed on the construction of positions to improve the quality of postgraduates (Zhang Qingbin, 1999) [31].

From the perspective of self-education, quality education for postgraduates should be implemented through purposeful and planned self-education for postgraduates (Xie Zhaoyuan, 1999)[32]. Cultivate self-study ability, pay attention to the study of basic theoretical knowledge, master solid basic skills and reasonable knowledge structure, as well as the ability to solve practical problems, etc. (Zhang Shihong [33], 2000).

\section{EVALUATION OF THE RESEARCH ON THE INNOVATION ABILITY OF DOMESTIC POSTGRADUATES}

From the above analysis, it can be seen that the research on China's innovation capacity lags behind that of foreign countries, which is inconsistent with the current high emphasis on innovation capacity. This lag is mainly reflected in the following aspects: 1) there are many theoretical speculations, but the empirical research is seriously insufficient; 2) there is a certain blindness in the recognition and rejection of foreign research results, without its own verification, and it has not really achieved the goal of "keeping the essence and discarding the dross"; 3) the research field is too narrow to keep pace with foreign research, the application research in its practical field has not been given enough attention; 4) affected by the "exam-oriented education" in the past, the evaluation of creative education experiment mostly focuses on the knowledge acquisition and "helps students enter higher education", with less focus on individual creative development and less quantitative empirical research [34].

\section{CONCLUSION}

From the domestic research on innovation ability, we can summarize the following characteristics: (1) in China, the research on innovation ability is still in the primary stage, not deep enough, the research scope is narrow; (2) the previous research on innovation ability, especially the research on the cultivation of the innovation ability of postgraduates, is mainly based on the qualitative research method, and the quantitative research method is rarely used; (3) more foreign theoretical references, on the domestic innovation ability localization research is less, and more focused on empirical description; (4) the research on innovation ability, especially the research on cultivating the innovation ability of postgraduates, has gradually attracted the attention and attention of many scholars.

\section{REFERENCES}

[1] Joseph arrows-schumpeter. Theory of economic development. Beijing Commercial Press, 1990. pp.73

[2] organization for economic cooperation and development. Statistical manual of technological innovation (translated by the national bureau of statistics). Beijing: China Statistical Press, 1992. pp. 26-28

[3] Grube, H. E. \& Wallance, D. B. The case study Method and Evolving Systems Approach for Understanding Unique Creative People at work. pp. 93-115

[4] Feist G J. A structural mode of scientific eminence. Psychological Science, 1993, 4(2): 366-371

[5] Martindale, C. Creativity, Consciousness, and Cortical Arousal. Journal of Altered Present states of Consciousness, 1977(3): 69-87

[6] Boden, M. The Creative Mind. NY: Basic, 1990

[7] Lubart, T. I. \&Sternberg, R. J. In S. M. Smith, T. B. Ward\& Ronald, A Finke(Eds. ): The Creative Cognition Approach. Cambridge, MA: MIT Press, 1995: 271-302

[8] Cao Richang. General psychology. Beijing: People's Education Press, 1979. pp.310

[9] Jing Qicheng. Concise encyclopedia dictionary of psychology. Changsha: Hunan Education Press, 1991. pp. 289

[10] Huang Xiting. Introduction to psychology. Beijing: People's Education Press, 1991. pp. 476

[11] Zhu Zhixian, Lin Chongde. Developmental psychology of thinking. Beijing: Beijing Normal University Press, 1986

[12] Peng Danling. General psychology. Beijing: Beijing Normal University Press, 1988

[13] Zhang Chunxing. Modern psychology. Shanghai: Shanghai People's Publishing House, 1994 
[14] Zhang Qinglin et al. Handbook of creative research. Chengdu: Sichuan Education Press, 2002

[15] Zhao Guirong. On the cultivation of innovation ability in graduate education. Science and technology. Talent Market, 2002, (6): 34-36

[16] $\mathrm{Li}$ Fei. Research on the integration of undergraduate and graduate innovation ability training in key universities of science and engineering. Excellent doctoral and master thesis of Harbin Institute of Technology, 2002,8

[17] He Dezhong, Fang Zhenyun. Exploration and practice of graduate students' innovation ability. China Higher Education Research, 2004, (1) 27-28

[18] Huang Xinming, Wang Ping. A brief analysis on the cultivation of graduate students' innovation ability. China higher education, 1999, (18): 26-28

[19] Zhang Yingchun, Ding Yiqiang. Several factors affecting the cultivation of graduate students' innovation ability and countermeasures. Exploration of higher education, 2000, (2): 63-65

[20] Qian Cunyang. Analysis on obstacles and countermeasures for cultivating graduate students' innovation ability. Exploration of higher education, 2004, (1): 52-54

[21] Zhang Youzhi, Li Zhi. An analysis of factors hindering the cultivation of postgraduates' innovation ability. Journal of China university of geosciences (social science edition), 2004, (3): 88

[22] Zhang Weigang et al. Reflections on postgraduate work after the authorization of first-level discipline. Degree and postgraduate education, 1999, (6)

[23] Hu Zhide. A brief discussion on interdisciplinary training of graduate students' innovation. Degree and Graduate Education, 2001, (1)
[24] Ren Bing. Optimizing the curriculum structure of liberal arts master students and promoting the reform of graduate teaching. Degree and Graduate Education, 1999, (2)

[25] Zhang Wenxiu et al. Cultivation of doctoral students' innovation ability. Degree and Postgraduate Education, 1999, (1)

[26] Ma Yongbin et al. Exploration of the collective construction of postgraduate scientific research. Degree and Postgraduate Education, 2000, (5)

[27] Geng Jun et al. Emphasis on the innovation of thesis proposal to ensure the innovation requirements. Degree and Graduate Education, 1999, (2)

[28] Qu Haidong, Zhang Liping. Reflections on the cultivation of postgraduate innovation ability. Higher Agricultural Education, 2002, (10): 70-72

[29] Yang Zhenhong. On innovative education and cultivation of graduate students' innovative ability. Degree and Graduate Education, 1999, (5)

[30] Yang Liangqi. Educational connotation and implementation approach of "three rural areas" activities in colleges and universities. Journal of Hunan Business School, 1999, (3)

[31] Zhang Qingbin. Giving full play to the role of cultural quality education of college student associations, correspondence education, 1999, (1)

[32] Xie Zhaoyuan. Self-cultivation of trans-century college students innovative quality. Theoretical Guide, 1999, (11)

[33] Zhang Shihong. Strengthening the cultivation of innovative ability of postgraduates. Journal of Hebei Agricultural University (agriculture and forestry education), 2000 (3): 27-28

[34] Zhang Qinglin. Handbook of creative research. Chengdu: Sichuan Education Press, 2002 